\title{
Decrease of Apoptosis Rate in Patients with Renal Transplantation Treated with Mycophenolate Mofetil
}

\author{
F.J. Pardo-Mindán ${ }^{a}$, P. Errasti ${ }^{\text {b }}$ A. Panizo ${ }^{\text {a }}$, I. Sola ${ }^{a}$ E. de Alava ${ }^{a}$, M.D. Lozano ${ }^{a}$
}

Departments of ${ }^{\mathrm{a}}$ Pathology and ${ }^{\mathrm{b}} \mathrm{Nephrology,} \mathrm{Clínica} \mathrm{Universitaria,} \mathrm{Universidad} \mathrm{de}$ Navarra, Pamplona, Spain

\author{
Correspondence: F.J. Pardo-Mindán \\ Dpto. Anatomía Patológica, \\ Clínica Universitaria Universidad de Navarra. \\ E-31080 Pamplona (Spain) \\ Tel. +34 48 255400, Fax +34 48172294 \\ E-Mail: jpardo@unav.es
}

\begin{abstract}
Background/Aims

Mycophenolate mofetil (MMF) is a powerful immunosuppressant that inhibits the proliferation of lymphocytes by blocking the enzyme inosine monophosphate dehydrogenase. MMF prevents acute graft rejection in organ transplants. The aim of this investigation is to study whether MMF has any influence on apoptosis and proliferation rates of cells other than lymphocytes.
\end{abstract}

\section{Methods}

We conducted a retrospective study of renal allograft biopsies taken during the 1st week after transplantation in 25 patients receiving triple therapy with prednisone, ciclosporin and azathioprine $75 \mathrm{mg}$ /day and in 25 patients treated with MMF at a dose of $2 \mathrm{~g} /$ day instead of azathioprine, in order to investigate the differences in the proliferation and apoptosis rates of the glomerular, tubular, interstitial and endothelial cells of the kidney. Twelve normal kidneys were used as controls. Conventional histopathological techniques were applied as usual for pathological diagnosis. Proliferative activity was assessed by use of MIB-1 antibody. Sections of formalin-fixed, paraffin-embedded tissue blocks were stained for the presence of apoptotic cells by TUNEL assay. Evaluation of proliferative or apoptotic rates was made by counting the number of positive cells in 10 glomeruli and in 10 transversely cut tubuli in each biopsy. The positive cells in the interstitium were counted in ten high-power fields. Positive cells in the endothelium were scored semiquantitatively from 0 to 3 : $0=$ none, $1=$ isolated cells, $2=$ small groups of cells, $3=$ most endothelial cells. Mann-Whitney $U$ and chi-square tests were used for intergroup comparisons. 


\section{Results}

All biopsies were normal or had borderline (Banff classification) acute rejection. MIB-1 rates were similar in both groups, without statistical differences $(p>0.05)$ between them. Significantly lower apoptotic rates were found in the group treated with MMF in tubular epithelium $(23.41 \pm 8.86$ vs. $57.4 \pm 13.42 ; p=0.021)$, in glomerular $(1.25 \pm 0.78$ vs. $5.3 \pm 1.66 ; p=0.027)$, and interstitial cells $(1.58 \pm 0.6$ vs. $5.8 \pm 1.54 ; p=0.043)$. Apoptosis in endothelial cells ( $\mathrm{p}>0.05$ ) was similar in both groups.

\section{Conclusion}

We conclude that treatment with MMF of kidney transplant patients does not affect the proliferative rate of cells of the allograft, but decreases the number of apoptotic cells in tubular epithelium.

\section{KEY WORDS}

Mycophenolate mofetil

MIB-1

TUNEL

Apoptosis

Renal transplantation 


\section{INTRODUCTION}

Mycophenolate mofetil (MMF) is a semisynthetic derivative of the antimetabolite mycophenolic acid which inhibits the enzyme inosine monophosphate dehydrogenase (IMPDH). This enzyme catalizes the conversion of inosine to guanine monophosphate which is required for purine synthesis during mitoses. In solid-organ transplantations, MMF prevents acute graft rejection, inhibiting $\mathrm{T}$ and $\mathrm{B}$ cell proliferation $[\mathrm{I}]$ which induces death of tubular epithelial cells by apoptosis which is followed by epithelial regeneration [2].

The efficacy of MMF in preventing acute rejection, through inhibition of IMPDH, must have some influence over other proliferating cells. There is an initial loss of tubular epithelial cells by apoptosis after transplantation that sometimes is important enough to cause true tubular necrosis and renal insufficiency. Epithelial proliferation occurs in the early phase after tubular necrosis, and excess hyperplastic epithelial cells regress during the repair process by cell desquamation and apoptosis, both of which are essential for the recovery of the original tubular structure [3-5]. The fact that immunosuppression with MMF results in a markedly reduced number and grade of acute rejection episodes [1], suggests a protective role of this drug over all renal cells.

The aim of this work is to study the influence of MMF treatment on both apoptosis and proliferation of different cell types in renal allografts during the 1st week after transplantation, in the absence of acute rejection.

\section{MATERIALS AND METHODS}

\section{Biopsy Specimens}

A total of 75 renal biopsy specimens were selected on the basis of clinical history. Cases were classified as follows:

Group A comprised 25 specimens from normal kidneys collected at autopsy from patients who died less than $6 \mathrm{~h}$ before of causes unrelated to renal pathology.

Group B included 25 biopsy specimens taken between days 4 and 7 after renal transplantation. The patients received triple therapy with prednisone, ciclosporin and azathioprine at a dose of $75 \mathrm{mg} / \mathrm{day}$. The levels of ciclosporin were maintained at 250$350 \mathrm{ng} / \mathrm{ml}$ at the time of biopsy. Renal function at biopsy was normal in all cases. Biopsies of groups B and C (see below) were taken following a protocol which included a biopsy during the lst week after transplantation.

Group C consisted of 25 specimens taken during the lst week after renal transplantation. The patients received triple therapy with prednisone, ciclosporin and MMF at a dose of $2 \mathrm{~g} /$ day, following the criteria of Ducloux et al. [1, 6]. The levels of ciclosporin were maintained at $250-350 \mathrm{ng} / \mathrm{ml}$ at the time of biopsy. Renal function at biopsy was normal in all cases. 
The age of the patients was similar in all groups (mean 46, range 22-61 years). All patients were transplanted in our institution with similar technique and time of ischemia. All biopsies of the groups B and $\mathrm{C}$ were normal or had borderline (Banff classification) acute rejection. Signs of tubular necrosis were absent in all specimens.

Sections from formalin-fixed, paraffin-embedded tissue blocks were stained with conventional histopathological techniques including hematoxylin-eosin, periodic acidSchiff, Masson's trichrome, methyl green-pyronin and silver methenamine.

\section{Inmunostaining}

Proliferative activity was assessed by immunoreactivity to ki67 antibody (done MIB-1; Immunotech, Marseille, France), using the standard avidin-biotin-peroxidase complex (DAKO) method. The ki67 is a carefully selected synthetic immunogen which ascertains a very high specificity: it labels proliferating cells in man and many other mammalian species [7]. Simultaneous staining was performed for MIB-1 and negative controls which included substitution of the monoclonal primary antibody for mouse myeloma proteins of the same subclass and concentration as the monoclonal antibody.

Sections were deparaffinized in xylene, rehydrated through graded alcohols and incubated 2 x 5 min in citrate buffer ( $\mathrm{pH}$ 6.0) in a household microwave oven at $800 \mathrm{~W}$. After microwave exposure, the slides were allowed to cool down to room temperature. The slides were briefly washed with Tris-buffered saline $(\mathrm{pH}=7.4)$ and incubated for $20 \mathrm{mM}$ with $3 \% \mathrm{H}_{2} \mathrm{O}_{2}$ in water to block endogenous peroxidase activity. MIB-1 antibody was used at 1:100 dilution and incubated for $30 \mathrm{~min}$ at room temperature. Biotinylated antimouse/rabbit antibody (DAKO) at a dilution 1:100 was used as the linking molecule. After washing, avidin-biotin-peroxidase complex was applied, and aminoethyl carbazole was used for visualization.

\section{In situ Apoptosis Assay}

Sections from selected formalin-fixed, paraffin-embedded tissue blocks were placed on coated slides. This study was conducted to examine the occurrence of apoptotic cell death in formalin-fixed, paraffin-embedded biopsy specimens from allografted kidneys by the terminal deoxynucleotidyl transferase-mediated deoxyuridine triphosphate-biotin nick end labeling (TUNEL) method, using digoxigenin-conjugated deoxyuridine triphosphate and anti-digoxigenin antibody labelled with peroxidase. Briefly, tissue sections were dewaxed and rehydrated routinely. After rehydration, the slides were incubated with proteinase $\mathrm{K}(20 \mathrm{mg} / \mathrm{ml})$ at room temperature for $15 \mathrm{~min}$. Endogenous peroxidase was inactivated by $3 \%$ hydrogen peroxide. Tissue sections were stained with an ApopTag system (Oncor, Gaithersburg, Md., USA) that identifies cells with internucleosomal fragmentation of DNA (apoptosis). The procedure was performed according to the manufacturer's instructions. The reaction was terminated after $60 \mathrm{~min}$ by transfer of the slides to a Coplin jar containing prewarmed working strength stopwash buffer and incubated for $30 \mathrm{~min}$ at $37^{\circ} \mathrm{C}$. The sections were then covered with 55 $\mathrm{ml}$ of anti- digoxigenin-peroxidase and incubated for $30 \mathrm{~min}$ at room temperature and stained with diaminobenzidine to detect the biotin-labelled nuclei. 
The method is based on the preferential binding of terminal deoxynucleotidyl transferase to the 3'-hydroxyl ends of DNA. Briefly, residues of digoxigenin deoxyuridine triphosphate were catalytically added to the ends of DNA fragmenta with the enzyme terminal deoxynucleotidyl transferase.

Deionized water was used instead of terminal deoxynucleotidyl transferase for negative controls. Positive controls for immunohistochemistry and TUNEL assay consisted of inflamed human tonsils. Cells were considered to be apoptotic when a strong brown nuclear reactivity was observed.

\section{Evaluation}

A blind study was made of all slides by two different observers, counting the median value for each appraisal. Evaluation of proliferative or apoptotic rates were made counting the number of positive cells in 10 glomeruli and in 10 transversely cut tubuli in each biopsy specimen. The positive cells in the interstitium were counted in ten highpower fields. Positive cells in the endothelium were scored semiquantitatively from $\mathrm{O}$ to 3: $0=$ none, $1=$ isolated cells, $2=$ small groups of cells, $3=$ most endothelial cells.

\section{Statistics}

Data are expressed as mean \pm SEM. In order to study the differences in the proliferation and apoptosis rates of the glomerular, tubular, interstitial and endothelial cells of the kidney, data were analyzed using the chi- squared test. Normally distributed, multiplesample, continuous data were analyzed with analysis of variance, while those with nonnormal distribution were analyzed using the Mann-Whitney $U$ test. $p<0.05$ was considered significant.

\section{RESULTS}

Microscopically all biopsies were normal or showed small groups of lymphocytes without tubulitis. Isolated mitoses or eosinophilic bodies were occasionally found in tubuli.

MIB-1 rates in glomeruli, tubular epithelial cells, interstitial cells and endothelium were similar in groups B and C, without statistical differences ( $p>0.05$; table 1, fig. 1). MIB1 antibody was only positive in the nuclei of isolated tubular or glomerular cells and in lymphocytic infiltrate.

TUNEL positivity was occasionally observed in groups $\mathrm{B}$ and $\mathrm{C}$ in all cellular types (glomerular, tubular, interstitial and endothelial cells). In general, significantly lower apoptotic rates were found in the group treated with MMF (group C) as compared with group $B$ in glomerular $(1.25 \pm 0.78$ vs. $5.3 \pm 1.66 ; \mathrm{p}=0.027)$, tubular $(23.41 \pm 8.86$ vs. $57.4 \pm 13.42 ; \mathrm{p}=0.021)$ and interstitial $(1.58 \pm 0.6$ vs. $5.8 \pm 1.54 ; \mathrm{p}=0.043)$ cells (table 2; fig. 2). In the MMF group (group C), $91.66 \%$ of the cells studied had grade 0-1 endothelial apoptosis, whereas only $40 \%$ of the cells in group B had grade 0-1 
endothelial apoptosis $(p=0.03)$. Isolated apoptotic cells were found in tubuli of normal kidneys (group A). The distribution of apoptotic cells within the graft was homogeneous without preference for any localization.

\section{DISCUSSION}

Over the past decades, treatment with ciclosporin, azathioprine and prednisone has been widely considered to be the most effective combination for prophylactic immunosuppression following cadaveric renal transplantation [6]. The use of MMF instead of azathioprine reduces the incidence and severity of biopsy-proven acute rejection $[1,6]$, and decreases the need for multiple courses of steroids and the use of antilymphocyte preparations for treatment of rejection $[8,9]$. MMF does not change the incidence of death as compared with the other treatment group, but prolongs allograft survival in many laboratory animals $[10,11]$. In this paper we have tried to demonstrate the role of MMF in the protection of tubular epithelium during the 1 st week after transplantation, studying selected renal biopsy specimens without acute rejection or tubular necrosis.

MMF is rapidly converted to mycophenolic acid, a potent inhibitor of IMPDH which lastly reduces guanine nucleotide pools. It selectively inhibits DNA synthesis and guanosine triphosphate dependent metabolic events [12], which are essential for mitoses in many cell types, including $\mathrm{T}$ and $\mathrm{B}$ lymphocytes [1]. MMF may exhibit a marked antiproliferative effect without toxicity in mono-nuclear cultures through inhibition of the production of cytokines [13] or block the ability of cytokine receptors to activate cell cycling, interfering with clonal expression [14]. MMF inhibits proliferation of cells other than lymphocytes, such as smooth muscle cells in rat aortic allografts [15], but this effect is not universal, since we have demonstrated that it does not inhibit the proliferation of tubular epithelium: it allows the easy compensation of cell loss due to ischemia during the first days after transplantation [16].

Apoptotic cell death can be examined using several techniques, such as 3' end labeling with terminal transferase, gel fractionation, Southern blotting and other immunohistological techniques. It is generally accepted that apoptosis and necrosis cannot be differentiated using a single technique [17], but if there are no other reasons for necrosis, the TUNEL technique has been considered sufficient to demonstrate evidence of increased apoptotic cell death $[4,17]$. The main problem of the TUNEL technique is to distinguish between leukocytes and epithelial apoptotic cells when there is a well-established acute rejection episode.

Poor initial function is common in cadaveric renal transplantation and is usually attributed to tubular epithelial apoptosis brought about by ischemia during harvesting/implantation [3, 4, 18]. Apoptosis is also increased in renal tubular epithelial cells of patients having chronic [17] and acute [19] renal allograft rejection. The induction of apoptosis may be due to an imbalance between cytokine secretion and cytokine deprivation $[20,21]$ caused by MMF treatment. Nevertheless, caution must be exercised not to simply attribute the observed effects to the presence of MMF in the therapeutic regimen, but rather to the replacement of azathioprine by MMF or the interactions of the different drugs used in the triple-treatment regimes. It remains to be 
formally demonstrated that the addition of MMF to a dual-drug regimen would give the same results. $\mathrm{T}$ cell (and possibly macrophage) mediated cytotoxicity plays an important role in acute renal allograft rejection, particularly in the case of tubular injury, and furthermore suggests that apoptosis may be a mechanism not only for graft cell destruction, but also for elimination of activated $\mathrm{T}$ cells in the infiltrate [22].

MMF reduces the incidence of biopsy-proven acute rejection, the incidence of histologically severe rejection and the graft loss [1]. The maintenance of the capacity of proliferation of renal cells and the decrease of apoptosis rate have a worthy consequence to the patient. It is possible that MMF has a protective effect against apoptosis, which is a very important mechanism of cell loss in chronic rejection [23]. This would explain the prolonged allograft survival in many laboratory animals [8, 9]. Fas is expressed by tubular epithelium, but Fas-mediated apoptosis does not play a role in the induction of apoptosis during renal transplant rejection [24-26]; however, this mechanism may be very important in ischemia.

These data suggest that immunosuppression with MMF represents a more effective approach in renal transplantation, because it provides a protection against the loss of tubular epithelial cells by apoptosis. This is the first report which demonstrates a probable protective effect of MMF against apoptosis during the 1st week after transplantation, without changing the proliferation rate of other renal cell types. Further studies would be necessary to see whether MMF keeps this protective effect during long-term treatment.

\section{REFERENCES}

1. The Tricontinental Mycophenolate Mofetil Renal Transplantation Study Group: A blinded, randomized clinical trial of mycophenolate mofetil for the prevention of acute rejection in cadaveric renal transplantation. Transplantation 1996:61:10291037.

2. Robertson H, Wheeler J, Thompson V, Johnson JS, Kirby JA, Morley AR: In situ lymphoproliferation in renal transplant biopsies. Histochemistry 1995;104:331-334.

3. Shimizu A, Yamanaka N: Apoptosis and cell desquamation in repair process of ischemic tubular necrosis. Virchows Arch B Cell Pathol Incl Mol Pathol 1993;64:171-180.

4. Matsuno T, Sasaki H, Ishido N, Matsuda H, Sadamori H, et al: Apoptosis in human kidney allografts. Transplant Proc 1996;28:12261227.

5. Lieberthal W, Menza SA, Levine JS: Graded ATP depletion can cause necrosis or apoptosis of cultured mouse proximal tubular cells. Am J Physiol 1998;274:F315F327.

6. Ducloux D, Fournier V, Bresson-Yautrin C, Rebibou JM, Billerey C, Saint-Hillier Y, Chalopin JM: Mycophenolate mofetil in renal transplant recipients with cyclosporine-associated nephrotoxicity: A preliminary, report. Transplantation 1998;65:1504-1506.

7. Rose DSC, Maddox PH, Brown DC: Which proliferation markers for routine immunohistology? A comparison of five antibodies. J Clin Pathol 1994;47:10101014.

8. Gonwa TA: Mycophenolate mofetil for maintenance therapy in kidney transplantation. Clin Transplant 1996;10:128-130. 
9. Danovitch GM: Mycophenolate mofetil in renal transplantation: Results from US randomized trials. Kidney Int 1995;52(suppl):93-96.

10. Morris RE, Hoyt EG, Murphy MP, Eugui EM, Allison AC: Mycophenolic acid morpholinoethylester (RS-61443) is a new immunosuppressant that prevents and halts heart allograft rejection by selective inhibition of $\mathrm{T}$ - and $\mathrm{B}$-cell purine synthesis. Transplant Proc 1990;22: 1659-1662.

11. Bechstein WO, Schilling M, Steele DM, Hullet DA, Sollinger HW: RS61443/cyclosporine combination therapy prolongs canine liver allograft survival. Transplant Proc 1993;25:702703.

12. Ransom JT: Mechanism of action of mycophenolate mofetil. Ther Drug Monit 1995;17:681-684.

13. Nagy SE, Andersson JP, Andersson UG: Effect of mycophenolate mofetil (RS61443) on cytokine production: Inhibition of superantigen-induced cytokines. Immunopharmacology 1993;26:11-20.

14. Halloran PF: Molecular mechanisms of new immunosuppressants. Clin Transpl 1996;10: 118-123.

15. Raisanen Sokolowski A, Vuoristo P, Myllarniemi M, Yilmaz S, Kallio E, Hayry P: Mycophenolate mofetil (MMF, RS 61443) inhibits inflammation and smooth muscle cell proliferation in rat aortic allografts. Transpl Immunol 1995;3:342-351.

16. Shoskes DA, Halloran PF: Delayed graft function in renal transplantation: Etiology, management and long-term significance. J Urol 1996; 155:1831-1840.

17. Laine J, Etelamaki P, Holmberg C, Dunkel L: Apoptotic cell death in human chronic renal allograft rejection. Transplantation 1997;63: 101-105.

18. Parmar MS, Kjellstrand CM, Solez K, Halloran PF: Glomemlar endothelial cell detachment in paired cadaver kidney transplants: Evidence that some cadaver donors have preexisting endothelial injury. Clin Transplant 1994;8:120-127.

19. Ito H, Kasagi N, Shomori K, Osaki M, Adachi H: Apoptosis in the human allografted kidney: Analysis by terminal deoxynucleotidyl transferase-mediated DUTP-biotin nick end labeling. Transplantation 1995;60:794-798.

20. Lin Y, Benchimol S: Cytokines inhibit p53- mediated apoptosis but not p53mediated G1 arrest. Mol Cell Biol 1995;15:6045-6054.

21. Oyaizu N, McCloskey TW, Than S, Pahwa S: Inhibition of CD4 cross-linkinginduced lymphocyte apoptosis by vesnarinone as a novel immunomodulating agent: Vesnarinone inhibits Fas expression and apoptosis by blocking cytokine secretion. Blood 1996;87:2361.

22. Meehan SM, McCluskey RT, Pascual M, Preffer FI, Anderson P, Schlossman SF, Colvin RB: Cytotoxicity and apoptosis in human renal allografts: Identification, distribution, and quantitation of cells with a cytotoxic granule protein GMP-17 (TIA-1) and cells with fragmented nuclear DNA. Lab Invest 1997;76:639-649.

23. Wang J, Nonomura N, Ichimaru N, et al: Expression of Fas and Fas ligand in renal grafts with acute and chronic rejection in the rat model. J Interferon Cytokine Res 1997; 17:369.

24. Boonstra JG, van der Woude FJ, Wever PC, Laterveer JC, Daha MR, van Kooten CJ: Expression and function of Fas (CD95) on human renal tubular epithelial cells. J Am Soc Nephrol 1997;8:1517-1524.

25. Swenson KM, Ke B, Wang T, Markowitz JS, Maggard MA, Spear GS, Imagawa DK, Goss JA, Busuttil RW, Seu P: Fas ligand gene transfer to renal allografts in rats: Effects on allograft survival. Transplantation 1998;65:155-160.

26. Kato S, Akasaka Y, Kawamura S: Fas antigen expression and its relationship with apoptosis in transplanted kidney. Pathol Int 1997;47: 230-237. 


\begin{tabular}{|l|c|c|c|c|}
\hline \multicolumn{5}{|c|}{ Table 1. Proliferation rates in glomeruli, tubular epithelial cells and } \\
interstitial cells (Mann-Whitney U test) \\
\hline & Group A & Group C & Group B & p \\
\hline Glomeruli & $0.01 \pm 0.002$ & $0.33 \pm 0.18$ & $1.3 \pm 0.65$ & 0.31 \\
\hline Tubules & $0.3 \pm 0.1$ & $6.33 \pm 1.76$ & $7.1 \pm 2.02$ & 0.71 \\
\hline Interstitium & 0 & $3.83 \pm 1.35$ & $2.1 \pm 0.45$ & 0.5 \\
\hline
\end{tabular}

\begin{tabular}{|l|c|c|c|c|}
\hline \multicolumn{5}{|c|}{ Table 2. Apoptotic rates in glomeruli, tubular epithelial cells and } \\
interstitial cells (Mann-Whitney U test). \\
\hline & Group A & Group C & Group B & p \\
\hline Glomeruli & 0 & $1.25 \pm 0.78$ & $5.3 \pm 1.66$ & 0.027 \\
\hline Tubules & $0.1 \pm 0.03$ & $23.41 \pm 8.86$ & $57.4 \pm 13.42$ & 0.021 \\
\hline Interstitium & 0 & $1.58 \pm 0.6$ & $5.8 \pm 1.54$ & 0.043 \\
\hline
\end{tabular}




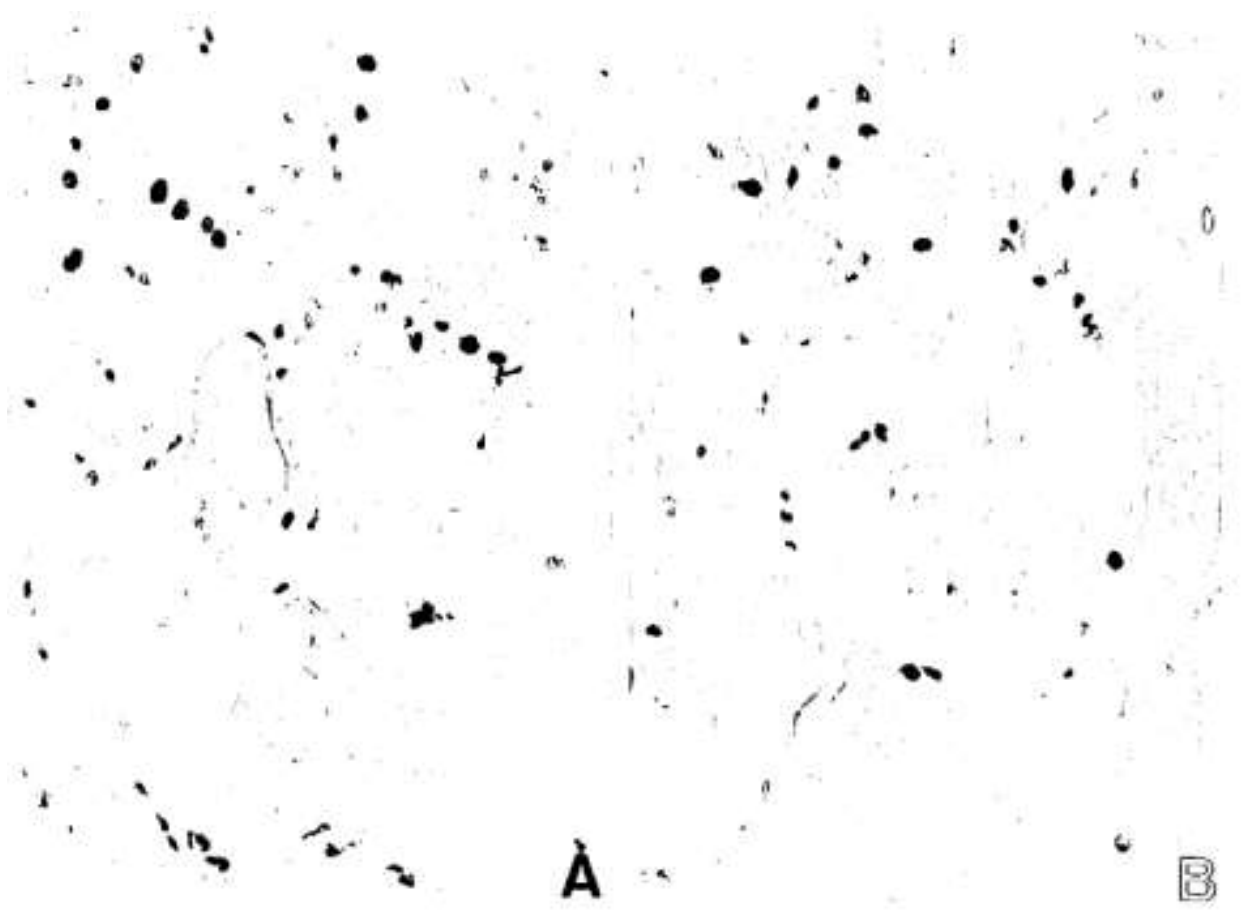

Figure 1. Immunohistochemical staining of renal biopsy specimens by MIB-1 antibody. A Treatment with MMF. $x$ 85. B Immuno-suppression with azathioprine. $x$ 170. The number of positive cells was similar in both groups. Light-green counterstain.

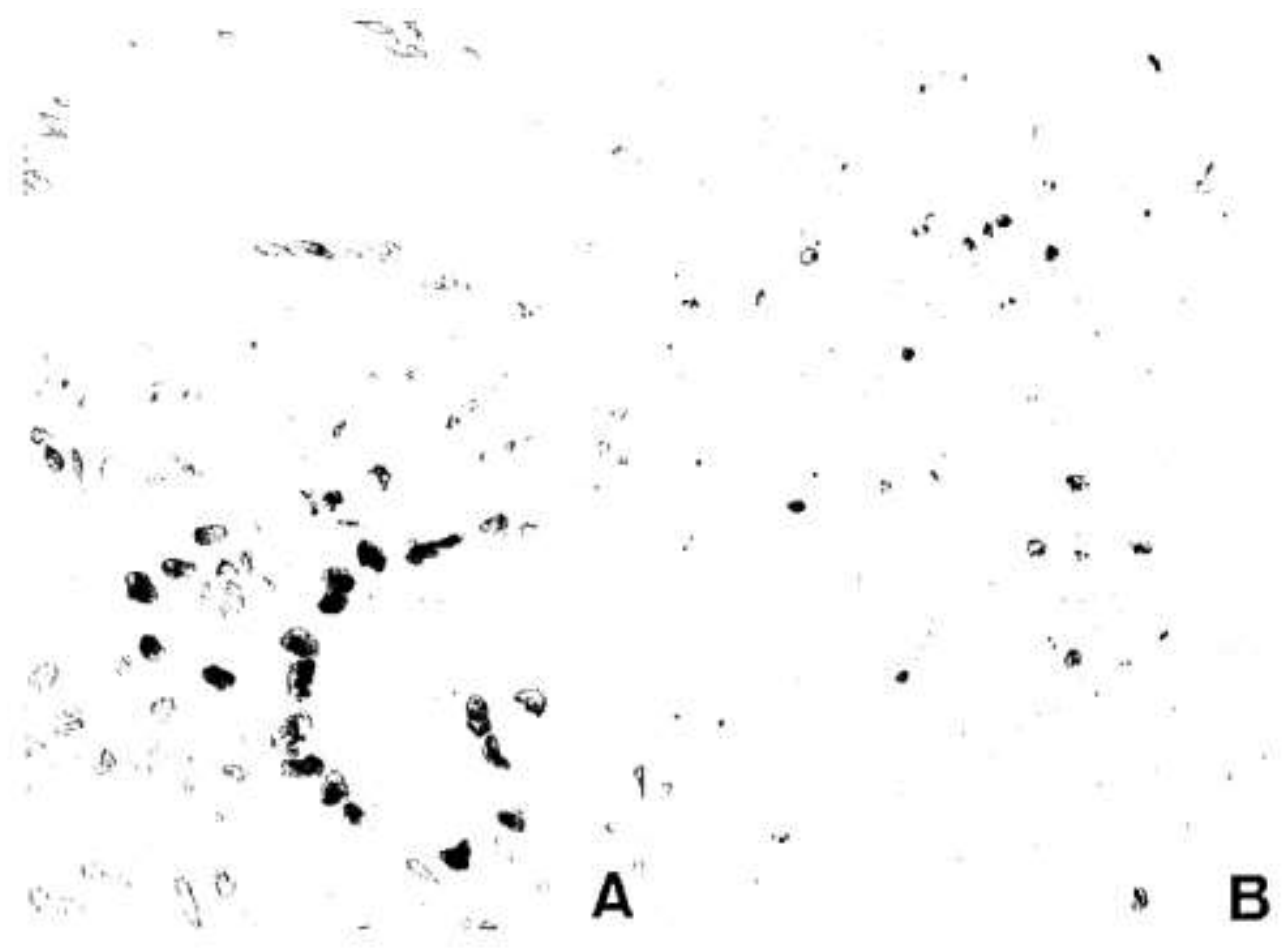

Figure 2. In situ assay for apoptosis. A Numerous positive nuclei in a kidney biopsy specimen of a patient treated with azathioprine. Note the positivity in endothelial cells. $x$ 170. B Isolated positive cells in a patient treated with MMF. x 85. Light-green counterstain. 